\title{
$\mathbb{1}$

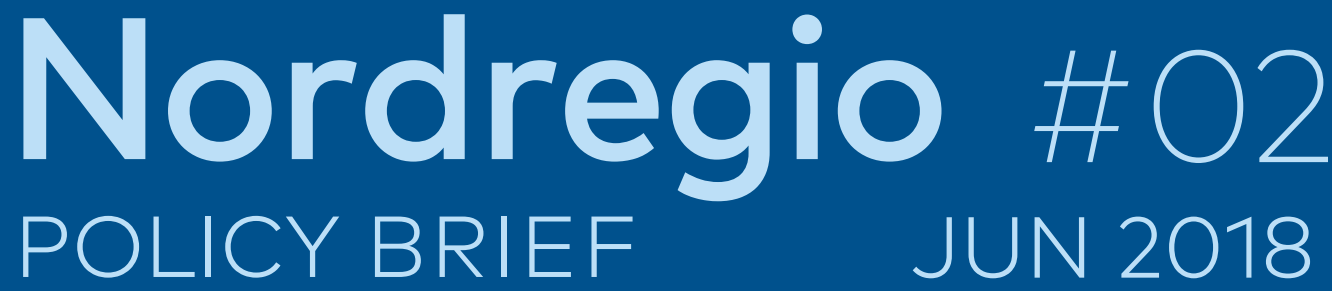

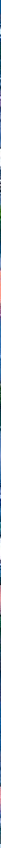

\section{Att skapa regioner och organisera för regional utveckling}

Regionerna är viktiga pusselbitar i de nordiska ländernas välfärdsystem inte minst inom sjukvårdsområdet och för kollektivtrafiken. Men regionernas roll i samhällsplaneringen är mer oklar. Regioner är både aktörer och arenor för att skapa hållbar utveckling. Regionernas form och funktion är dock inte en oproblematisk fråga, som politiker, planerare och forskare försöker finna svar på.

$\boldsymbol{\nu}$

Det experimenteras just nu mycket kring formell och informell regional organisering framför allt i de nordiska länderna. Syftet med denna text är att ge en kortfattad översikt över problematiken och vad forskningen berättar om att organisera regional utveckling och tillväxt, men också att lyfta fram några nordiska erfarenheter.
REGIONALT TILLVÄXTARBETE I SVERIGE

Den politiskt-administrativa organiseringen av regioner i Sverige har länge varit under diskussion och utredning, och under de senare åren har ett antal genomgripande reformförslag presenterats men inte genomförts. Däremot har det skett en rad förändringar vad gäller det regionala utvecklingsarbetet. På ett övergripande plan har ett skifte från regional omfördelningspolitik till 
regionalt tillväxtarbete skett, där det nu är regionerna som har ansvaret att stödja och skapa förutsättningar för tillväxt i regionen utifrån en marknadslogik snarare än en statlig omfördelningslogik.

Ansvaret för regional utveckling, eller som det numera heter, regionalt tillväxtarbete, är uppdelat på tre olika typer av institutioner; direktvalda landsting, kommunala samverkansorgan och länsstyrelser. Denna variation av organisationsformer för regionalt tillväxtarbete håller dock på att harmoniseras över landet genom det succesiva bildandet av så kallade regioner (som formellt är landsting med regionalt utvecklingsansvar).

Sedan januari 2017 finns det 14 stycken sådana regioner.Ideövrigasjulänenharlandstingeninlettarbetet med att bilda regioner eller redan ansökt om detta hos regeringen. Att bilda en region innebär att det regionala utvecklingsarbete som tidigare gjorts av kommunala samarbetsorganisationer eller länsstyrelser nu inkorporeras i landstingsorganisationen. Detta innebär att det regionala utvecklingsarbetet blir en del i en ny större organisation som även och framförallt arbetar med sjukvård och kollektivtrafik.

I förordningen om regionalt tillväxtarbete (2007:713) poängteras att: "Det regionala tillväxtarbetet bör utformas och bedrivas i sektorsövergripande samarbete mellan aktörer på lokal och nationell nivå. Arbetet kan också utformas och bedrivas i samarbete med aktörer på europeisk nivå". Detta skall bland annat ske genom att ta fram och genomföra ett så kallat regionalt utvecklingsprogram. Detta skall vara en samlad strategi för regionen som specificerar mål och prioriteringar utifrån ett hållbart regionalt tillväxtarbete utifrån de regionala förutsättningarna $i$ regionen. Det skall utarbetas i samråd med kommuner och landsting och även utgöra grunden för regionala strukturfondsprogram med mera.

Regionerna förväntas således vara en aktör som samordnar olika intressen både mellan administrativa nivåer men också mellan olika sektorer, en så kallad "multi-level coordination actor"1 med fokus på "policyintegration"2. Detta genererar dock en rad följdfrågor inte minst i samband med att de nya regionerna övertar det regionala utvecklingsansvaret från antingen kommunala samverkansorgan eller statliga länsstyrelser. Ska regionen vara till för kommunerna och stötta dem eller ska kommunerna stötta regionen? Relationen mellan staten och regionerna har gått mer mot att regionerna stöttar staten, men hur detta tar sig uttryck på regional nivå är mer oklart.

\section{REGIONEN INOM NORDISK SAMHÄLLSPLANERING}

I de nordiska länderna är den regionala nivån ganska svag i relation till den statliga nivån och de relativt självständiga kommunerna. Generellt verkar de nordiska länderna ha svårt att lämna ifrån sig kontroll till den regionala nivån, men den statliga politiska styrningen mellan länderna varierar och är under förändring. I ett specialnummer av tidskriften Scandinavian Journal of Public Administration från 2015 diskuteras den regionala styrningen i Norden, samt de olika reformer och experiment som genomförts på den regionala nivån under de senaste åren. Först och främst kan det konstateras att regionerna är ett rörligt landskap som kontinuerligt förändras och att ytterligare reformer redan föreslagits och även delvis förkastats (exempelvis i Sverige).

\section{TILLIT TILL OCH INOM REGIONAL NÄTVERKSSTYRNING}

Forskning visar på att svenskarnas förtroende för eller tillit till regionerna är om inte svagt så i alla fall likgiltig. ${ }^{3}$ Samtidigt pekar forskning på att den regionala nivån kanske är den mest adekvata nivån för att hantera många av utmaningarna med att skapa ett hållbart samhälle ${ }^{4}$. Detta skapar både direkta praktiska men även mer fundamentala demokratiska dilemman kring representativitet och legitimitet. De regionala institutionerna (som län och landsting) utmanas även av framväxten av olika typer av strategiska regioner och lokala och regionala partnerskap.

Ett annat dilemma är att de politiskadministrativa regionernas gränser inte överensstämmer med de funktionella regionerna. De lokala arbetsmarknadsregionernas gränser går ofta utanför länets gränser (exempelvis i Storstockholm) och ett län kan rymma flera arbetsmarknadsregioner (exempelvis i Dalarna). En funktionell region är dessutom inte statisk utan beroende av vilken funktion som är utgångspunkten. Om det är pendlingsavstånd eller vattenavrinningsområde som är den aktuella funktionen får regionen olika geografisk utbredning. Teoretiskt sett behöver heller inte en region vara ett kontinuerligt rum utan snarare bestå av relationer, länkar och noder. En lösning för att överkomma detta dilemma är olika former av strategiska partnerskap och nätverksstyrning som vuxit fram men som också skapar demokratiska dilemman kring legitimitet och transparens.

Tillit är i detta sammanhang väsentligt men det kan vara behjälpligt att särskilja mellan tillit till regional nätverksstyrning och tillit mellan olika aktörer inom nätverken. Det verkar vara svårt att öka tilliten till den regionala styrningen genom exempelvis statliga initiativ som kommer ovanifrån. En jämförande studie om regional planering i Danmark och England konstaterade att varken en formalisering av systemet eller en mer nätverksorienterande ansats ökade tilliten till den regionala planeringen ${ }^{5}$. En norsk studie visar däremot på att tillit mellan nyckelaktörer var avgörande i formandet av stadsregionerna Stavanger och Bergen vilka anses vara lyckade regionbildningarb. Nätverk verkar vara bra för lärande och kapacitetsbyggande vilket studier av Göteborgsområdet antyder?. För tjänstemän kan dock dessa informella nätverk vara mer betydelsefulla än formella resurser och institutionell makt ${ }^{8}$. 


\section{LÄRDOMAR}

\section{REGIONAL UTVECKLING OCH TILLVÄXT}

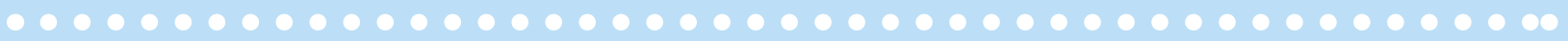

Regioner är politiska organisationer och förvaltningsorganisationer med ansvar för ett geografiskt område. Gränserna för den politisktadministrativa rådigheten överensstämmer emellertid sällan med de geografiska gränserna för de samhällsfrågor regionerna har att hantera. Detta innebär att man i hög grad organiserar sitt arbete i nätverk, i likhet med samhällsstyrning genom nätverk (s.k. governance). Det uppstår emellertid dilemman mellan nätverksorganisering över organisationsgränser och system för demokratisk styrning.
Regionen kan fungera som en koordinator mellan olika aktörer i det politiska flernivåsystemet kommuner, regioner och staten - och mellan olika sektorer - den offentliga och privata samt civilsamhället. Relationerna mellan kommunerna och regionen är dock avgörande för regionens roll att koordinera arbete för regional tillväxt. Tillit inom regionen mellan aktörerna i nätverken är viktigt för att ändamålsenlig samverkan ska uppstå, vilket kräver tydlighet, förståelse och tålamod. Att skapa tillit för den regionen inom området för det regionala utvecklingsarbetet är en ännu större utmaning, inte minst i en samhällsorganisation där den regionala nivån är relativt marginaliserad som i de nordiska länderna.

\section{REGIONBILDNINGEN I ÖSTERGÖTLAND}

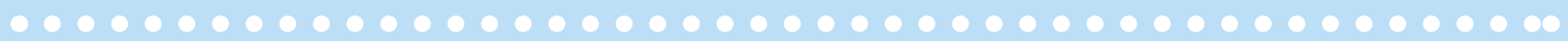

Den 1 januari 2015 bildades Region Östergötland. Detta var inte bara ett namnbyte från landsting till region utan innebar även att den nya organisationen tog över ansvaret för regionala utvecklings- och tillväxtfrågor från det kommunala regionförbundet (ÖSTSAM). Relationerna mellan den nybildade regionen och kommunerna i regionen har varit avgörande för regionbildningen vilket varit en läroprocess.

För att skapa en effektiv och fungerande organisation och samverkan för regionalt utvecklings- och tillväxtarbete har tre komponenter framkommit som särskilt viktiga:
Tydlighet: Det är en förutsättning att alla deltagare vet varför och hur man vill/kan/bör delta i arbetet och det bör finnas ett tydligt politiskt mandat för detta.

- Förståelse: Ändamålsenlig samverkan förutsätter ömsesidig förståelse för och kännedom om varandras organisationer och roller, inte minst vad gäller politiska prioriteringar.

Tålamod: Det tar tid att skapa en fungerande och ändamålsenlig organisation, och det behövs en förståelse för att framtida insatser till stor del bygger på tidigare erfarenheter.

\section{Noter:}

${ }^{1}$ G. Sandkjaer Hanssen, P.K. Mydske and E. Dahle, 'Multi-Level Coordination of Climate Change Adaptation: By National Hierarchical Steering or by Regional Network Governance?', Local Environment, 18/8 (2013), 869-87

2 S. Hovik and K.B. Stokke, 'Network Governance and Policy Integration - The Case of Regional Coastal Zone Planning in Norway', European Planning Studies, 15/7 (2007), 927-44.

${ }^{3}$ Eg. K.G. Hammarlund, 'Regional Reform and Citizen Participation in Sweden', Innovation, 17/2 (2004), 145-64; Anders Lidström, 'Commuting and Citizen Participation in Swedish City-Regions', Political Studies, 54/4 (2006), 865-88.

${ }^{4}$ Eg. A. Rodríguez-Pose, 'The Rise of the "City-Region" Concept and Its Development Policy Implications', European Planning Studies, $16 / 8$ (2008), 1025-46.

${ }^{5}$ M. Tait and C. Hansen, 'Trust and Governance in Regional Planning', Town Planning Review, 84/3 (2013), $283-312$.

${ }^{6}$ A.A. Farsund and A.K.T. Holmen, 'Towards a New Regional Landscape', Urban Research and Practice, 4/1 (2011), 23-37.

${ }^{7}$ M. Polk, 'Institutional Capacity-Building in Urban Planning and Policy-Making for Sustainable Development: Success or Failure?', Planning Practice and Research, 26/2 (2011), 185-206.

8 M. Sotarauta, 'Power and Influence Tactics in the Promotion of Regional Development: An Empirical Analysis of the Work of Finnish Regional Development Officers', Geoforum, 40/5 (2009), 895-905. 


\section{DE SVÅRFÅNGADE REGIONERNA}

En region kan betyda många saker. Ordets historia antyder att det handlar om såväl ett avgränsat område som om att styra (jfr. regera). En gemensam utgångspunkt hos många samhällsvetenskapliga forskare är dock att regioner är sociala konstruktioner, det vill säga det är institutioner skapade av samhället och inte naturgivna områden. Forskare närmar sig dock regioner på olika sätt beroende på disciplin och forskningsfråga. Hur olika infallsvinklar kompletterar och skiljer sig från varandra illustreras väl i antologin Det regionala samhällsbyggandets praktiker: tiden, makten, rummet (2013) där forskare från olika discipliner som historia, statsvetenskap, sociologi och kulturgeografi kritiskt analyserar det regionala samhällsbyggandets i Sverige.

En geografisk utgångspunkt kan exempelvis vara att betrakta en region som ett territorium eller landskap, ett annat sätt är att närma sig en region som en institution eller organisation inom det politisktadministrativa systemet. Att se en region i första hand som en karta eller som ett organisationsschema väcker olika frågor och ger olika svar.

Regioner finns på många olika skalor från internationella regioner som exempelvis EU, Norden eller Östersjöregionen till lokala arbetsmarknadsregioner. Oftast är det dock subnationella regioner som avses, det vill säga att en region placeras in mellan den nationella och den lokala nivån. I Sverige är det vanligtvis län, landsting eller landskap som det refereras till när regioner diskuteras.

De statliga länsstyrelserna och de direktvalda landstingen är dock två olika institutioner som opererar på den regionala nivån. För att det göra det än mer komplext så har nationella myndigheter sina egna regionala indelningar, Trafikverket har sex regioner medan Polismyndigheten har sju regioner. Bredvid dessa politiskt-administrativa regioner finns det även andra typer av exempelvis historiska och kulturella regioner som de svenska landskapen eller funktionella regioner som till exempel arbetsmarknadsregioner.

\title{
OM FORSKNINGSPROJEKTET
}

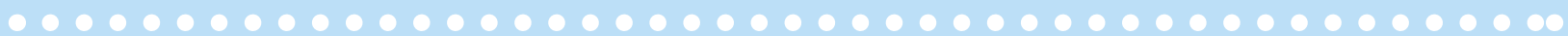

En viktig bakgrund till den här texten är forskningsprojektet: Ett regionalt utvecklingssystem? - Att organisera för regional utveckling i Östergötland. Detta projekt har drivits av Centrum för kommunstrategiska studier (CKS) vid Linköpings universitet i samverkan med forskare vid Nordregio och på uppdrag av Region Östergötland. Projektet har pågått från senare delen av 2015 till 2017. Projektet har haft flera delsyften, bland annat att identifiera och beskriva förväntningar bland nyckelaktörer i samband med bildandet av Region Östergötland från 1 januari 2015; att beskriva och analysera arbetsformer för regional utveckling $\mathrm{i}$ samband med regionbildningen (med fokus på relationer mellan regional och kommunal nivå). Det övergripande målet med studien har varit att utgöra ett stöd för regionen för att den skulle kunna utforma ändamålsenliga arbetsformer för sitt regionala utvecklingsarbete. Arbetet med projektet har omfattat intervjuer av omkring 50 informanter som främst representerar regionen och kommunerna. Resultaten är dokumenterade dels i några Arbetsnotat (tillgängliga via författarna på CSK) dels genom en publicerad rapport.

\section{Lås mer}

Hermelin, B. och Wänström, J. (2017) Att organisera för regional utveckling - Erfarenheter från regionbildning i Östergötland. Centrum för kommunstrategiska studier, Rapport 2017:7

\section{Forskare}

Lukas Smas

Nordregio och Kulturgeografiska institutionen,

Stockholms universitet

lukas.smas@humangeo.su.se

Brita Hermelin \& Johan Wänström

Centrum för kommunstrategiska studier (CKS),

Linköpings universitet

brita.harmelin@liu.se

\section{Kommunikation}

Johanna Feuk

johanna.feuk@nordregio.org

\section{Bild}

Max Boettinger, unsplash.com

ISSN 2001-3876

URL: doi.org/10.30689/PB2018:2.2001-3876

www.nordregio.org 